\title{
A Morphometric Study of Intercondylar Notch of Femur and its Clinical Significance
}

\author{
Prasanna Veera Kumar Attada ${ }^{1}$ \\ ${ }^{1}$ Associate Professor of Anatomy, NRI Institute of Medical Sciences, Sangivalasa, Visakhapatanam 531162, India.
}

\section{Abstract}

Background: The lower end of femur has condyles and in between the condyles there is a gap called an intercondylar notch. The anterior cruciate ligament (ACL) is lodged in the notch. The ACL is closely related to the roof of the notch. A narrow notch can result ACL tear .Because of the clinical importance of notch morphology to ACL tears and as not many studies are there in the literature on dry bone; this morphological study on the intercondylar notch of femur was done. Subjects and Methods: The study was done on 30 dry femurs (15 right and 15 left femurs). The parameters obtained for the study were the width and depth of the intercondylar notch and the width and depth of the femoral condyles. The study included noting down the shape of the intercondylar notch. The intercondylar notch width index and its depth index were calculated with the above parameters. Results: It was observed that the intercondylar notch was having inverted ' $U$ ' shape morphology in $14(46.66 \%)$ specimens and was inverted ' $V$ ' shaped in 16 (53.34\%) specimens. The mean intercondylar notch width and depth, and width and depth of femoral condyles are $18.49 \pm 11.8,26.95 \pm 12.7,73.79 \pm 14.5,56.18 \pm 13.7$ respectively. P value and statistical significance, the two-tailed P value equals $0.58,0.39,0.84,0.82$ respectively for the width and depth of the intercondylar notch and the width and depth of the femoral condyles for the right and left femurs. By conventional criteria, this difference is considered to be not statistically significant. The notch width index and notch depth index are 0.25 and 0.47 respectively in the study. Conclusions: The present study has provided additional information on this subject .Bony morphological studies as well as the radiological studies combined with the correlated clinical studies are required to understand the pathology of ACL tears.

Keywords: Femoral condyles, anterior cruciate ligament.

Corresponding Author: Dr. Prasanna Veera Kumar Attada, Associate Professor of Anatomy, NRI Institute of Medical Sciences, Sangivalasa, Visakhapatanam 531162, India.

Received: October 2018

Accepted: October 2018

\section{Introduction}

The lower end of femur is enlarged and presents two rounded and eccentrically curved femoral condyles; and a notch separates these femoral condyles posteriorly called the intercondylar notch. ${ }^{[1]}$ The intercondylar notch lodges the attachment of anterior cruciate ligament of the knee joint (ACL). ${ }^{[2]}$ Jeremy M Burnham et al. in their article reiterated that, no bony morphologic feature had been more studied in the context of ACL injury than the intercondylar notch. They added that, a PubMed search in June 2017 revealed over 350 articles on the topic of intercondylar notch and ACL. ${ }^{[3]}$

The roof of the intercondylar notch of the femur has an inclination of 40 degrees to the longitudinal axis of the femur; and in full extension of the knee joint the roof of the notch is near to the anterior surface of the ACL. ${ }^{[4]}$

It is mentioned in the literature that, Palmar I, for the first time reported that a narrow intercondylar notch of femur can result in increased risk of ACL tears. ${ }^{[5]}$ Souryal et al observed that the notch width index, as the criterion to estimate risk of ACL injury. ${ }^{[6]}$ Shepstone L et al. observed that the intercondylar notch shape may be of importance because femora could be of equal notch width (or notch width index) but have different shapes; and differently shaped notches could provide very different volumes of space for the cruciate ligaments. The shape of the notch may have a more direct impact on the functioning of the ACL. ${ }^{[7]}$ Many studies had reported the existence of the correlation between the stenosis of the intercondylar notch and the tears of the ACL. ${ }^{[8,9]}$ Some studies also reported no such correlation. ${ }^{[10-12]}$ Anderson et al, in their study concluded that the shape of the notch may be of some significance (in relation to ACL damage), though further work is needed in this area. ${ }^{[13]}$

In spite of the clinical significance of the relation between the intercondylar notch and the ACL tears only few studies are available on dry femur in the literature. The aim of the study is undertake morphology and morphometry of the intercondylar notch on dry femur. 


\section{Subjects and Methods}

The study was done on 30 dry femurs (15 right and 15 left femurs). The femurs with damages and pathologies around the intercondylar notch were excluded from the study. The study was approved by our institutional ethics committee. The parameters obtained for the study were the width and depth of the intercondylar notch and the width and depth of the femoral condyles [Figure 1-3]. The study included noting down the shape of the intercondylar notch [Figure 4-5].

The study was done in the inferior view of the femoral condyles, showing the shape of the intercondylar notch as well as the notch width and depth. . The shape of the notch was noted; either as inverted U or inverted V shaped. All the measurements were taken with the help of digital vernier calipers; which provides precision readings from $0.01 \mathrm{~mm}$ and $0.0005 \mathrm{~mm}$. The notch width was measured at the widest part of the intercondylar notch at about its middle [Figure $1 \mathrm{CD}$ ]. The depth of the notch was measured as the height of the notch and was measured to its maximum [Figure $1 \mathrm{AB}$ ]. The femoral condylar width was measured as the distance between the medial border of medial condyle of femur to lateral border of lateral femoral condyle [Figure $2 \mathrm{EF}]$. The depth of the femoral condyles was measured as the anteroposterior length of the lateral femoral condyle as mentioned by Wada et al [Figure $3 \mathrm{GH}] .{ }^{[14]}$

The intercondylar notch width index and its depth index were calculated with the above parameters. The notch width index was calculated as: $\mathrm{CD} / \mathrm{EF} \mathrm{X} 100$. The notch depth index was calculated as $\mathrm{AB} / \mathrm{GH} \times 100$.

All the measurements were taken by the same observer and each measurement was taken thrice and averaged and the mean value was noted.

\section{Statistical Analysis}

The data obtained in the study was analysed by descriptive statistics and was expressed as mean \pm standard deviation (SD) and SEM. The statistical comparison of differences between right and left femurs was done with help of $t$-test for unpaired .The Statistical significances are noted at $\mathrm{P}<$ 0.05. The GraphPad was the statistical online software used for the analysis.

\section{Results}

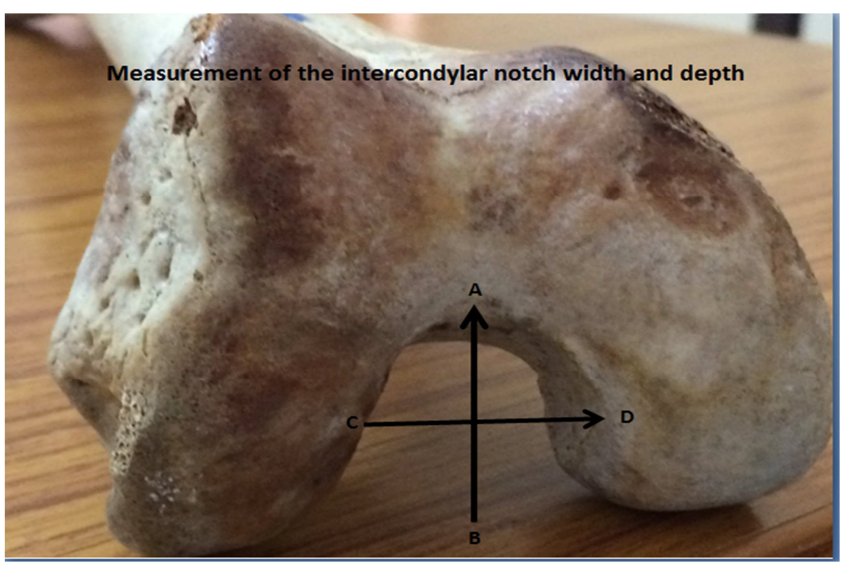

Figure 1: Showing measurement of intercondylar notch: width C-D; depth A-B.

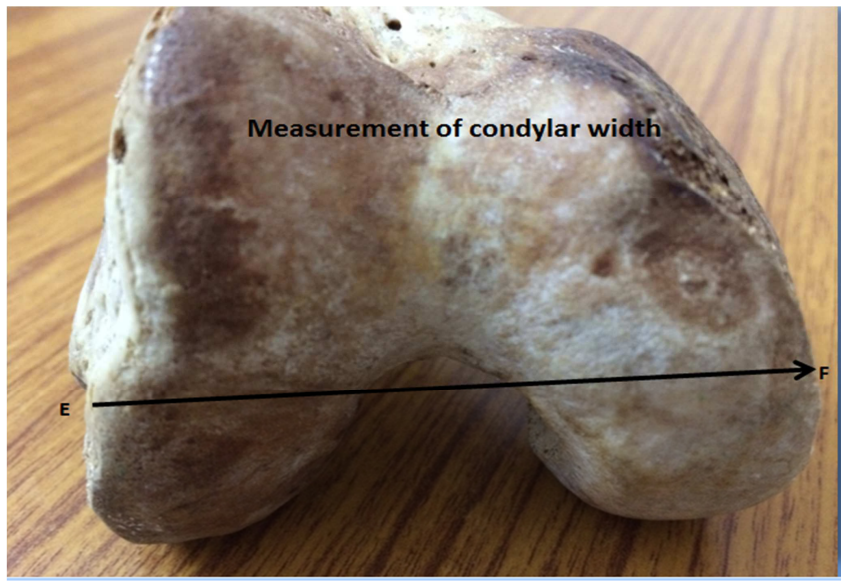

Figure 2: Showing measurement of condylar width: E-F.

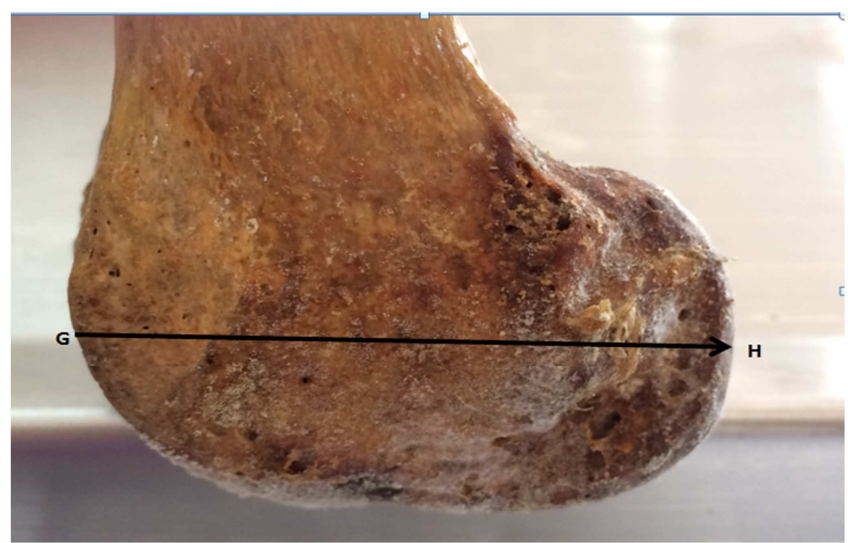

Figure 3: Showing measurement of condylar depth : G-H.

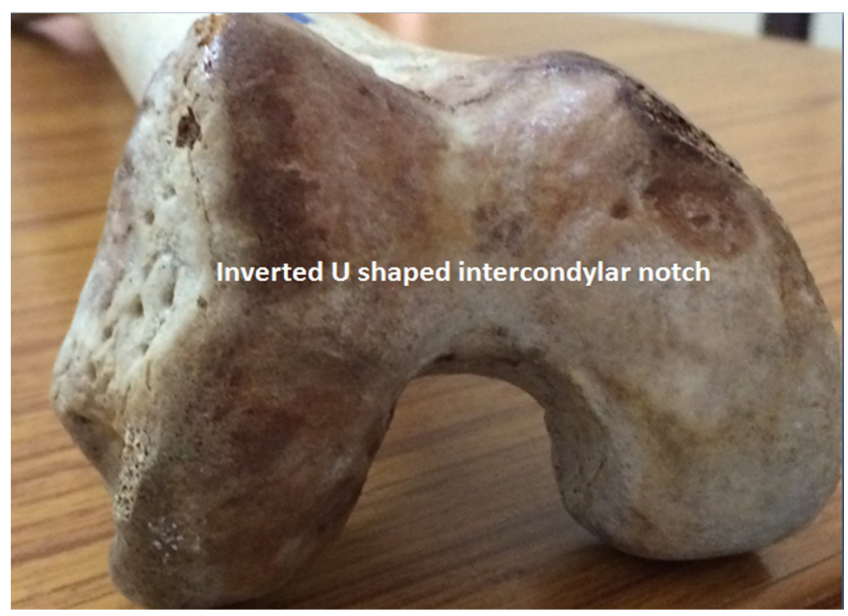

Figure 4: Showing U shaped intercondylar notch.

It was observed that the intercondylar notch was having inverted ' $U$ ' shape morphology in $14(46.66 \%)$ specimens [Figure 4] and was inverted ' $\mathrm{V}$ ' shaped in 16 (53.34\%) specimens [Figure 5].

The mean intercondylar notch width and depth, and width and depth of femoral condyles are $18.49 \pm 11.8,26.95 \pm 12.7$, $73.79 \pm 14.5,56.18 \pm 13.7 \mathrm{~mm}$, respectively [Table 1]. The SEM results of the study show that the sampled data of the study was from a population that was distributed according to a Gaussian distribution.

$P$ value and statistical significance 


\section{Attada; Marphametric Study of Intercandylar Natch of Femur}

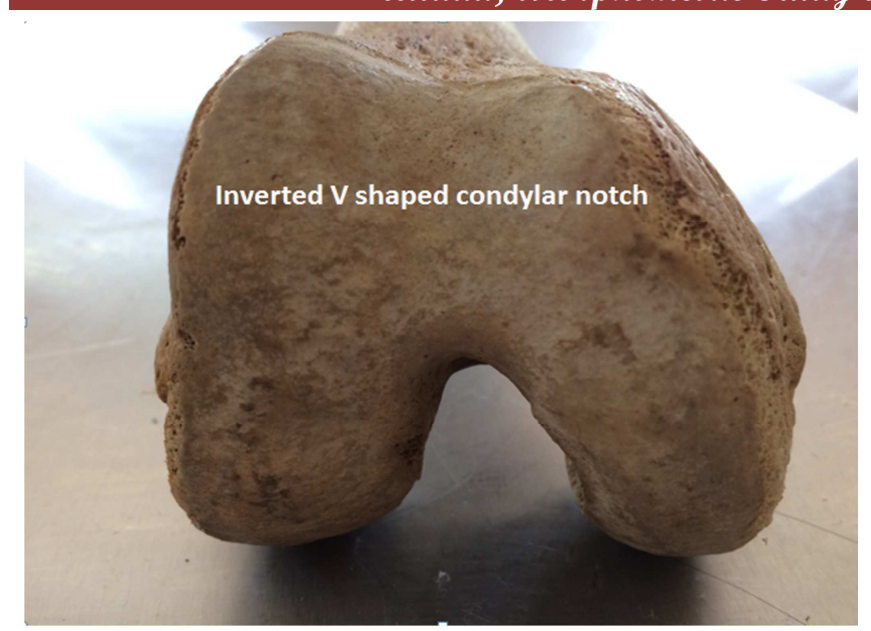

Figure 5: Showing V shaped intercondylar notch.

Table 1: Morphometry of femoral intercondylar notch and femoral condyles

\begin{tabular}{|c|c|c|}
\hline Values in $\mathrm{mm}$ & Total $(n=30)$ & SEM \\
\hline Intercondylar notch width & $18.49 \pm 11.8$ & 2.17 \\
\hline Intercondylar notch depth & $26.95 \pm 12.7$ & 2.33 \\
\hline Condylar width & $73.79 \pm 14.5$ & 2.65 \\
\hline Condylar depth & $56.18 \pm 13.7$ & 2.51 \\
\hline
\end{tabular}

Table 2 Comparison of the morphometric data of right and left side femurs

\begin{tabular}{|l|l|l|l|l|}
\hline $\begin{array}{l}\text { Values in } \\
\text { mm } \pm \text { SD }\end{array}$ & $\begin{array}{l}\text { Right } \\
\text { side } \\
(\mathbf{n}=\mathbf{1 5})\end{array}$ & $\begin{array}{l}\text { Left } \\
\text { side } \\
(\mathbf{n}=\mathbf{1 5})\end{array}$ & $\begin{array}{l}\text { Statistical } \\
\text { significance }\end{array}$ & Remarks \\
\hline $\begin{array}{l}\text { Intercondylar } \\
\text { notch width }\end{array}$ & $\begin{array}{l}18.7 \\
\pm 8.4\end{array}$ & $\begin{array}{l}18.2 \pm \\
8.4\end{array}$ & $\begin{array}{l}0.58 \\
(\mathrm{P}<0.05)\end{array}$ & $\begin{array}{l}\text { Statistically } \\
\text { not } \\
\text { significant }\end{array}$ \\
\hline $\begin{array}{l}\text { Intercondylar } \\
\text { notch depth }\end{array}$ & $\begin{array}{l}26.9 \pm \\
9.0\end{array}$ & $\begin{array}{l}26.9 \pm \\
9.0\end{array}$ & $\begin{array}{l}0.39 \\
(\mathrm{P}<0.05)\end{array}$ & $\begin{array}{l}\text { statistically } \\
\text { not } \\
\text { significant }\end{array}$ \\
\hline $\begin{array}{l}\text { Condylar } \\
\text { width }\end{array}$ & $\begin{array}{l}72.8 \pm \\
10.2\end{array}$ & $\begin{array}{l}74.7 \pm \\
10.2\end{array}$ & $\begin{array}{l}0.84 \\
(\mathrm{P}<0.05)\end{array}$ & $\begin{array}{l}\text { statistically } \\
\text { not } \\
\text { significant }\end{array}$ \\
\hline $\begin{array}{l}\text { Condylar } \\
\text { depth }\end{array}$ & $\begin{array}{l}56.1 \pm \\
9.7\end{array}$ & $\begin{array}{l}56.2 \pm \\
9.7\end{array}$ & $\begin{array}{l}0.82 \\
(\mathrm{P}<0.05)\end{array}$ & $\begin{array}{l}\text { statistically } \\
\text { not } \\
\text { significant }\end{array}$ \\
\hline
\end{tabular}

Table 3: Comparison of the present study with the morphometric data of various studies

\begin{tabular}{|l|l|l|l|l|}
\hline $\begin{array}{l}\text { Values in } \\
\mathbf{m m} \pm \text { SD }\end{array}$ & $\begin{array}{l}\text { Ravichandran } \\
\text { and Melani } \\
\text { 2010[15] }\end{array}$ & $\begin{array}{l}\text { Ameet K J } \\
\text { and } \\
\text { Murlimanju } \\
\text { BV2014[21] }\end{array}$ & $\begin{array}{l}\text { Sujay } \\
\text { Mistri } \\
\mathbf{2 0 1 5} \\
{[\mathbf{2 2}]}\end{array}$ & $\begin{array}{l}\text { Present } \\
\text { study } \\
\mathbf{2 0 1 8}\end{array}$ \\
\hline $\begin{array}{l}\text { Intercondylar } \\
\text { notch width }\end{array}$ & 18.77 & 17.9 & 18.82 & 18.49 \\
\hline $\begin{array}{l}\text { Intercondylar } \\
\text { notch depth }\end{array}$ & 27.24 & 26.3 & 27.31 & 26.95 \\
\hline $\begin{array}{l}\text { Condylar } \\
\text { width }\end{array}$ & 74.27 & 72.9 & 74.21 & 73.79 \\
\hline $\begin{array}{l}\text { Condylar } \\
\text { depth }\end{array}$ & 58.54 & 57.3 & 52.70 & 56.18 \\
\hline NWI & 0.25 & 0.25 & 0.25 & 0.25 \\
\hline NDI & 0.467 & 0.46 & 0.51 & 0.47 \\
\hline
\end{tabular}

The two-tailed $\mathrm{P}$ value equals $0.58,0.39,0.84,0.82$ respectively for the width and depth of the intercondylar notch and the width and depth of the femoral condyles for the right and left femurs. By conventional criteria, this difference is considered to be not statistically significant [Table 2].
The notch width index and notch depth index are 0.25 and 0.47 respectively in the study.

\section{Discussion}

Shepstone L et al mentioned that there were many human and animal studies which reported the correlation between the femoral intercondylar notch width and ACL injury. ${ }^{[7]}$ Ravichandran D and Melani R opined that; the space available for the ACL is determined by the dimensions of notch including the depth, width and shape. ${ }^{[15]}$ Anderson et al in their study found a smaller notch width in those subjects with severe osteoarthritis (OA) than in those with less severe or no OA. In their study of notch width and knee OA they reported that damage to the ACL was only found in those subjects with severe disease and suggested that a narrowing of the notch occurs after the onset of OA, leading to ACL damage, knee instability, and disease progression. ${ }^{[13]}$ Stein $\mathrm{V}$ et al observed that the relationship between narrow notch width and increased ACL injury risk has been confirmed not just in young patients with acute ACL tears, but also in older patients with knee arthritis. ${ }^{[16]}$ Wada et al mentioned that the notch - depth index has been used by some authors to predict the stenosis of intercondylar notch. ${ }^{[12]}$ Wolf MR et al observed that in general, an notch width index (NWI) of $<0.27$ or an absolute notch width of $<15 \mathrm{~mm}$ is considered a significant risk factor for ACL injury. ${ }^{[17]}$ Studies on notch size had observed that a smaller notch size often correlates with a smaller ACL, suggesting that the increased injury risk could partially be due to a weaker ACL. ${ }^{[18-20]}$

In the present study it was observed that the intercondylar notch was having inverted ' $U$ ' shape morphology in $46.66 \%$ and inverted ' $\mathrm{V}$ ' shaped in $(53.34 \%)$ specimens. The mean of intercondylar notch width and depth, and width and depth of femoral condyles were, $18.49 \pm 11.8,26.95 \pm 12.7$, $73.79 \pm 14.5,56.18 \pm 13.7 \mathrm{~mm}$ respectively. The notch width index and notch depth index were 0.25 and 0.47 respectively.

According to Indian study by Ravichandran D and Melanie $\mathrm{R}$, the average notch width index was found to be 0.25 and the average notch depth index was found to be 0.46 in cadaver dry bones. ${ }^{[15]}$ Ameet $\mathrm{K} \mathrm{J}$ and Murlimanju BV in their study made observations almost similar to Ravichandran and Melanie findings with respect to mean intercondylar notch width and depth, condylar width and depth, notch width index and notch depth index. ${ }^{[21]}$ Ravichandran and Melanie observed inverted ' $U$ ' and inverted ' $\mathrm{V}$ ' shaped notches in $67 \%$ and $33 \%$ of their specimens. ${ }^{[15]}$ In the study by Ameet $\mathrm{K} \mathrm{J}$ and Murlimanju $\mathrm{BV}$, the inverted ' $\mathrm{U}$ ' shape was found in $73.2 \%$ of cases and inverted ' $\mathrm{V}$ ' shaped in $26.8 \%$ cases. These are almost similar to Ravichandran and Melanie findings. ${ }^{[15]}$ [Table 3] gives comparison of the present study with the morphometric data of various studies which includes another study by Sujay Mistri and his observations were similar to the other studies. ${ }^{[22]}$ The findings of the present study are similar to the studies mentioned.

It was reported that the intercondylar notch was found to be smaller in knees with severe osteoarthritis because of 
osteophytic growth in the notch, ${ }^{[14]}$ thus increasing the incidence of ACL ruptures in patients with degenerative arthritis. ${ }^{[23]}$ Alizadeh \& Kiavash reported that there was no observed relationship between the narrow femoral intercondylar notch width and the tears of ACL. ${ }^{[24]}$

\section{Conclusion}

Jeremy M Burnham et al in their article observed that until recently, bony morphology has been underappreciated in the field of ACL research. They further observed that there is still much that is unknown about the causes, consequences, and variations in bony morphology relative to ACL injury; it is crucial that surgeons and scientists continue their pursuit of knowledge and understanding of these factors; as there exists great variability among individuals; incorporation of bony morphology into preoperative planning, operative techniques, and postoperative rehabilitation and return-toplay will be crucial to providing individualized treatment of ACL injuries. ${ }^{[3]}$

We believe that the present study has provided additional information on this subject and these morphological data might be of use to the clinicians who are involved in the diagnosis and management of knee problems.

\section{References}

1. Williams, P.L., Bannister, L.H., Berry, M.M. : Gray's Anatomy. 38th edition. Edinburgh and London: ELBS with Churchill Livingstone; 1995; 680.

2. Van Eck, C.F., Martins, C.A., Vyas, S.M., Celentano, U., van Dijk, C.N., Fu, F.H. Femoral intercondylar notch shape and dimensions in ACL-injured patients. Knee Surg Sports Traumatol Arthrosc . 2010; 18(9): 1257-62.

3. Jeremy M Burnham .Bony morphologic factors affecting injury risk, rotatory stability, outcomes, and re-tear rate after anterior cruciate ligament reconstruction. Ann Joint 2017;2:44

4. Miller, R.H.Knee Injuries. Campbell's Operative Orthopaedics. Volume 3. 11th edition. Mosby: Elsevier; 2008; 2496-2550

5. Palmer, I. On the injuries to the ligaments of the knee joint: a clinical study. 1938. Clin Orthop Relat .2007;Res 454: 17-22.

6. Souryal, T.O., Moore, H.A., Evans, J.P. Bilaterality in anterior cruciate ligament injuries: associated intercondylar notch stenosis. Am J Sports Med 1988; 16(5): 449-54.

7. Shepstone, L., Rogers, J., Kirwan, J.R., Silverman, B.W. Shape of the intercondylar notch of the human femur: a comparison of osteoarthritic and non-osteoarthritic bones from a skeletal sample. Ann Rheum Dis .2001; 60(10): 968-73.

8. Good, L., Odensten, M., Gillquist, J. Intercondylar notch measurements with special reference to anterior cruciate ligament surgery. Clin Orthop Relat Res .1991; (263): 185-9.

9. Davis, T.J., Shelbourne, K.D., Klootwyk, T.E. Correlation of the intercondylar notch width of the femur to the width of the anterior and posterior cruciate ligaments. Knee Surg Sports Traumatol Arthrosc 1999; 7(4): 209-14

10. Schickendantz, M.S., Weiker, G.G. The predictive value of radiographs in the evaluation of unilateral and bilateral anterior cruciate ligament injuries. Am J Sports Med .1993; 21(1): 110-3.

11. Herzog, R.J., Silliman, J.F., Hutton, K., Rodkey, W.G., Steadman, J.R. Measurements of the intercondylar notch by plain film radiography and magnetic resonance imaging. Am J Sports Med .1994; 22(2): 204-10.

12. Lombardo, S., Sethi, P.M., Starkey, C. Intercondylar notch stenosis is not a risk factor for anterior cruciate ligament tears in professional male basketball players: an 11-year prospective study. Am J Sports Med.2005; 33(1): 29-34.

13. Anderson AF, Lipscomb AB, Liudahl KJ, Addlestone RB. Analysis of the intercondylar notch by computed tomography.Am J Sports Med $.1987 ; 15: 547-52$.

14. Wada, M., Tatsuo, H., Baba, H., Asamoto, K., Nojyo, Y. Femoral intercondylar notch measurements in osteoarthritic knees. Rheumatology (Oxford) .1999; 38(6): 554-8.

15. Ravichandran, D., Melani, R. Morphology of the intercondylar notch and its clinical significance. International Journal of Anatomical Sciences 1:2010 26-30.

16. Stein V, Li L, Guermazi A, et al. The relation of femoral notch stenosis to ACL tears in persons with knee osteoarthritis. Osteoarthritis Cartilage. 2010;18:192-9.

17. Wolf MR, Murawski CD, van Diek FM, et al. Intercondylar notch dimensions and graft failure after single- and double-bundle anterior cruciate ligament reconstruction. Knee Surg Sports Traumatol Arthrosc .2015;23:680-6.

18. Chandrashekar N, Slauterbeck J, Hashemi J. Sex-based differences in the anthropometric characteristics of the anterior cruciate ligament and its relation to intercondylar notch geometry: a cadaveric study. Am J Sports Med. 2005;33:1492-8.

19. Wolters F, Vrooijink SH, Van Eck CF, et al. Does notch size predict ACL insertion site size? Knee Surg Sports Traumatol Arthrosc .2011;19:S17-21.

20. Dienst M, Schneider G, Altmeyer $\mathrm{K}$, et al. Correlation of intercondylar notch cross sections to the ACL size: a high resolution MR tomographic in vivo analysis. Arch Orthop Trauma Surg $.2007 ; 127: 253-60$.

21. Ameet K J and Murlimanju BV Morphometric Analysis of Intercondylar Notch of Femur with Emphasis on Its Clinical Implications Med \& Health 2014; 9(2): 103-108

22. Sujay Mistri A study of femoral condylar morphometry Indian Journal of Basic and Applied Medical Research; September 2015: Vol.-4, Issue- 4, P. 500-510

23. Leon, H.O., Blanco, C.E., Guthrie, T.B., Martinez, O.J. Intercondylar notch stenosis in degenerative arthritis of the knee. Arthroscopy . 2005;21(3): 294-302.

24. Alizadeh, A., Kiavash, V. 2008. Mean intercondylar notch width index in cases with and without anterior cruciate ligament tears. Iran J Radiol.2008; 5(4): 205-8.

Copyright: ( $)$ the author(s), publisher. Academia Anatomica International is an Official Publication of "Society for Health Care \& Research Development". It is an open-access article distributed under the terms of the Creative Commons Attribution Non-Commercial License, which permits unrestricted non-commercial use, distribution, and reproduction in any medium, provided the original work is properly cited.

How to cite this article: Attada PVK. A Morphometric Study of Intercondylar Notch of Femur and its Clinical Significance. Acad. Anat. Int. 2018;4(2):10-13.

DOI: dx.doi.org/10.21276/aanat.2018.4.2.4

Source of Support: Nil, Conflict of Interest: None declared. 